\title{
Editorial: Managing expectations - How many new CRM systems can now 'manage' your customer to do anything?
}

Before we convince everyone to ante up for the latest and greatest system for an interactive, real-time, web-based CRM system, let us make sure we are really clear about exactly what customer relationship management will do for our very own customers. Right now it seems hard to argue with a system that will let you know every customer's own extensive preferences so you can then treat every single customer in exactly the way he or she likes to be treated presenting exactly the right amount of exactly the right information in exactly the right way at exactly the right time to clinch a sale. Don't get me wrong, I am not anti-CRM. But I am against the ante for CRM unless you know the exact benefits you will reap for your customers.

If 75 per cent of your industry's sales come in August at the annual trade show, will you get full use out of an annualised campaign-management capability? Will full knowledge of your customer's preference for blue bolt heads ever translate into modifying company colours on a tractor assembly line? Maybe it will, but the only way you will know is by detailed study and tests to establish needs and expectations specific to your industry and your customers, before you take the capital dive into the CRM pond.

The papers in this Journal of Database Marketing will help to establish those needs and expectations. 'I wouldn't start from here', by Neil Woodcock and Michael Starkey, strikes at just that concept: setting a solid CRM implementation plan in concrete on top of a vague foundation, with predictable problems. Leonard Paas and Ton Kuijlen present a paper not about what CRM is not, which seems to clog the headlines of many magazines these days, but what CRM is, and how you might get your arms around it in your own daily work.

On the same long view, Dr Alan Tapp presents the first of a series of three papers that take a critical look at the strategic value of direct marketing, beginning in this issue with what we are good at. A second paper by Dr Troy Festervand and Dr Susan Harmon looks at the increasing importance of the eXtensible Markup Language (XML) in our industry, and concludes that marketing students should have some understanding of XML and its derivatives. Bruce McDoniel and Patrick Monteleone present the first of two parts of a paper entitled 'Simulation and optimisation in direct marketing'. Abbott, Stone and Buttle report on a qualitative study into the implementation of CRM strategies. Dr Sachar Paulus looks at security processes in e-business and Shaun Doyle's software review examines how geography is used to support marketing activities in a range of industry sectors. 
So, as the glitter and hype chip off the CRM block, we are starting to see companies trying to get down to the business of applying its strengths to real-world marketing challenges. As so many times before in business development, careful examination and management of expectations holds the key to effective and profitable implementation. The issue in your hands should help to move you in the right direction.

SCOTT W. TILDEN

Editorial Board

July 2001 
